\title{
The Influence of Infill Wall Topology and Seismic Characteristics on the Response and Damage Distribution in Frame Structures
}

\author{
Nikos Nanos and David Begg \\ School of Civil Engineering and Surveying, University of Portsmouth, Portsmouth PO1 3AH, UK \\ Correspondence should be addressed to Nikos Nanos; nikos.nanos@port.ac.uk
}

Received 9 August 2013; Revised 5 November 2013; Accepted 6 November 2013

Academic Editor: Anaxagoras Elenas

Copyright (C) 2013 N. Nanos and D. Begg. This is an open access article distributed under the Creative Commons Attribution License, which permits unrestricted use, distribution, and reproduction in any medium, provided the original work is properly cited.

This paper identifies the effects of infill wall existence and arrangement in the seismic response of frame structures utilising the global structural damage index after Park/Ang $\left(\mathrm{GDI}_{\mathrm{PA}}\right)$ and the maximum interstorey drift ratio (MISDR) to express structural seismic response. Five different infill wall topologies of a 10-storey frame structure have been selected and analysed presenting an improved damage distribution model for infill wall bearing frames, hence promoting the use of nonstructural elements as a means of improving frame structural seismic behaviour and highlighting important aspects of structural response, demonstrating the suitability of such element implementation beyond their intended architectural scope.

\section{Introduction}

In their theory regarding the seismic behaviour of masonry infilled frames Paulay and Priestley [1] called for alteration, the existence of such infill elements bring, to the structural system: resulting in improved overall lateral load capacity. More contemporary work [2] has utilised the bracing of moment resisting steel frames as a means of improving the existing seismic response characteristics with great benefit. On the other hand, from site surveys and results of analytical and experimental analysis, it is widely acknowledged that infill walls contribute to the modal response of the structure.

Identifying these possible, positive effects the Federal Emergency Management Agency (FEMA) prepared FEMA 273 [3] in the NEHRP Guidelines for the Seismic Rehabilitation of Buildings provisions, dictating that concrete frames with infill walls must be constructed in such a way as to ensure infill element and frame interact under design loads. The reasons behind such contribution usually being related to the effect of infill walls on the overall building structural rigidity, the structure's natural period, and damping coefficient. Similarly, in steel frame structures, a lot of effort has been spent on research into the contribution of infill walls on seismic characteristics; leading to the identification of several important properties of infill walls in terms of their contribution to overall seismic behaviour.

In this paper the numerical relationship between infill wall existence in a frame structure and the overall structural response in case of seismic loading is investigated. The existence of infill walls in frame structures as well as their contribution to the seismic response has been a major point of study from various researchers in the past in an attempt to establish the relationship between the frame lateral load capacity and the existence of frame infill [4]. This fundamental research has further been enhanced with tests and observations of actual buildings during earthquakes.

With the advent of new and improved methods of recording, the significant role of infill on overall structure's seismic response has been established [5]. Klingner and Bertero [6] described the superiority of infilled frames over their bare frame counterparts with respect to energy dissipation and resistance to incremental collapse as well as the benefits of increased strength and energy absorption capacities. One can therefore see the potential advantages of infill wall inclusion in the design process that can possibly outweigh the detrimental effects of an increase in inertial forces due to their presence. 
The above have been the point of further research in terms of infilled frames and their ability to improve structural response during seismic excitation over the years [7, 8]. More work has been carried out on the issue of partially infilled frames, where openings are present, in an effort to address the issue of seismic behaviour a more diverse population of structures $[9,10]$ showing the significance of infill wall presence in frame structures. One notable exception to the above has been identified in the case of partial-height infill walls that often cause columns to experience nonductile shear failures (short column effect) rather than respond in a ductile and predominately flexural manner as intended [11].

From the seminal work of Polyakov [12] that first used the equivalent diagonal strut analogy for replacing the infill wall a lot of ground has been covered with an array of researchers studying the effect of infill walls in the seismic response of frame structures. Smith and Coull [13] presented a design method for infilled frame based on the diagonal strut bracing frame criteria taking under consideration the three possible modes of failure of the infill element. These were the shear failure along the masonry; the diagonal cracking through masonry; and the infill corner crashing, all assuming that a frame must be designed on the basis of gravity loading. D'Ayala et al. [14] highlighted in his work the importance of proper modelling characteristics to ascertain the validity of the infill model damage propagation. Smith and Carter [15] examined multistorey infilled frames with respect to lateral loading and proposed the equivalent strut concept focusing on the composite behaviour of infilled frame and failure modes. The factors affecting the effective width of diagonal compression strut were determined and the relevant design curves to estimate equivalent strut width, cracking and crushing strength of the infill element were given.

The above details of infill wall modelling are not explicitly covered in this work by the use of overall structural damage indices instead of examining the particular infill wall damage development. This enables the researchers to qualitatively address the infill wall contribution as well in an effectively more general form.

Regarding the type of infill wall material several different suggestions have been investigated in the past, each one with its own merits and limitations. Bruneau and Bhagwagar [16] studied the effects of steel and other ductile materials as well as steel plates, while Di Sarno and Elnashai [2] focused on frame bracing, all showing improvement in the overall structural response. Of the aforementioned the most easily applicable and readily available material is masonry infill. It can therefore be considered as a rather interesting solution for frame structure's seismic rehabilitation despite the apparent shortcomings in terms of additional weight added to the structure.

The extent of infill wall application as well as its individual frame coverage has been a point of extensive research in the past with restrained or partially restrained infill wall frames showing improved seismic characteristics [17]. Nevertheless, the difficulty to achieve this kind of restrain in frames that has not been designed for this purpose renders this a solution with limited practical use for structural rehabilitation. Most recently Tasnimi and Mohebkhah [18] once more demonstrated the beneficial contribution of both solid and nonsolid infill walls in individual frames' seismic response, while specific numerical models to study the above have been proposed [19]. This kind of in depth analysis would be out of the scope of this paper that concentrates on the overall structural characteristics of steel moment resisting frame structures and it would be of little consequence when the importance is shifted to a macro, building-wise scale.

\section{Proposed Methodology}

2.1. Overview. Having established the beneficial effects of infill walls in the seismic response of frame structures the importance of identifying the actual structural behaviour and damage distribution of a building becomes evident in assessing the actual contribution of the different infill wall topologies. Therefore, greater effort must be spent in the integration of the existing research into a generalized framework that will allow researchers and other interested parties to assess and quantify not only the effects of the existence of infill walls in a frame structure but also account for the different possible topologies and their subsequent effects.

It is the intention of this research not only to provide a study on the effect of different infill wall topologies for a specific structure but also act as a methodology that can be implemented for the identification of the best possible infill wall arrangement. Essentially, an optimisation tool that can be utilised in both new and retrofitted structures to assess the effectiveness of different wall arrangements according to possible structural and architectural constrains. Such an implementation can effectively yield the particular characteristics of seismic behaviour for different infill wall topologies and allow for a thorough overview of all available solutions before resulting in a more detailed study of the structural system. This is the main reason behind the suitability of a solution that remains essentially agnostic of the microscale seismic effects, on an element basis, but rather concentrates on the overall damage distribution and seismic behaviour. Either being based on global or regional damage indices instead of detailed calculations on a structural element basis. This research was based on addressing the issue of the overall seismic behaviour in a way that will account for the differences in alternative infill wall topologies and provide the seismic response characteristics of a frame structure.

The main objective of this paper is to provide a framework rather than a specific study of the infill wall contribution in seismic structural response. Due to the above and because the methodology presented is intended to act as a research tool for the identification of the intervention guidelines for potential seismic rehabilitation the whole process was built upon the merit of generalization. It has therefore been ensured that the proposed assessment methodology can, according to the research and implementation needs and with the necessary modifications, address the overall structural seismic response for a variety of structural types; infill elements; and seismic conditions. 
This paper identifies and quantifies the effects of solid, industrialized, clay infill wall existence and arrangement in the seismic response of frame structures highlighting their potential seismic design significance. To achieve the above, several artificial accelerograms compatible with the Greek Antiseismic Code [20] have been composed and a nonlinear dynamic analysis has been carried out to provide the structural response for the given seismic excitations. The global structure damage index after Park/Ang $\left(\mathrm{GDI}_{\mathrm{PA}}\right)$ and the maximum interstorey drift ratio (MISDR) have been selected as some of the most widely utilized structural seismic response parameters in contemporary state of art. Furthermore, their storey level equivalents ( $\mathrm{LDI}_{\mathrm{PA}}$ and LISDR) assess the more regionalized seismic behaviour.

For the structure under investigation, the creation of a simple analytical model of a typical commercial steel frame 10 storey building and the application of 4 different infill wall layouts resulting in 5 different structure types were realised. All structural elements and connections were designed in such way as to be in compliance with the relevant recent Euro codes for steel and antiseismic structures for steel moment resisting frame buildings. By utilising the EC3 [21] and EC8 [22] codes, respectively, to effectively represent a typical contemporary steel structure.

The use of spectrum compatible artificial accelerograms was selected to enable the production of a wide range of response data that share a common ancestry and allowed for executing a range of comparative studies between them, something not possible if naturally occurring ground motions were utilized. In light of the above, a set of 225 EC8 spectrum compatible accelerograms conforming to the Greek national annex requirements as described in the Greek antiseismic code have been created to assess the behaviour of the aforementioned models in a wide range of seismic excitations in their operating environment and a series of nonlinear dynamic analyses have been executed to record this behaviour.

2.2. Synthetic Accelerograms. The seismic excitations used for the dynamic analyses in this study are based on artificial accelerograms created to be compatible with the design spectra of the current Greek antiseismic code. The reason for choosing this approach rather than relying on natural accelerograms was dictated by the need to have a sufficiently large database for statistical reasons. For the creation of the aforementioned artificial accelerograms the program SIMQKE [23] has been utilized. With the use of a differentiated choice of seismic parameters 225 artificial accelerograms have been created all compatible to EC8 response spectra [22] in reference with the Greek seismic characteristics, as those are described in the relevant antiseismic codes of practice.

The aforementioned parameters were the peak ground acceleration (PGA), the total duration $\left(T_{D}\right)$ of the seismic event (with $T_{D}$ values of $20 \mathrm{~s}, 30 \mathrm{~s}$, and $40 \mathrm{~s}$ ), and the design spectra acceleration $(\alpha)$ for all three Greek seismic regions (nominal $\alpha$ equal to $0.16 \mathrm{~g}, 0.24 \mathrm{~g}$, and $0.36 \mathrm{~g}$ ) which have been used with 5 pseudorandom generator allocated numbers each to approximate the inherent variability of the seismic phenomenon without any reduction factors. All generated spectra were calculated based on the assumption of category B subsoil, deep deposits of medium dense sand, or overconsolidated clay at least $70 \mathrm{~m}$ thick, as described in EC8 [22] and incorporated in the Greek Antiseismic Code [20] to represent the most common Greek subsoil type.

For all recorded nonlinear analyses, the maximum interstorey drift ratio (MISDR) and the global structural damage index after Park/Ang $\left(\mathrm{GDI}_{\mathrm{PA}}\right)$ [24] have been evaluated as widely accepted direct methods of postseismic structural damage evaluation, based on the simplicity and straightforwardness of their calculation. Furthermore, for the specific needs of this project the level damage index after Park/Ang $\left(\mathrm{LDI}_{\mathrm{PA}}\right)$ and the local maximum interstorey drift ratio (LISDR) have also been used to express the relevant values on a level basis to demonstrate the distribution characteristics recorded.

2.3. Damage Indices. As explained previously, attention is focused on damage indicators that consolidate all member damage into one single value that can be easily and accurately used for the statistical exploration of the interrelation with the also single-value seismic parameters in question. Thus, in the GDI model after Park/Ang [24] the global damage is obtained as a weighed average of the local damage at the ends of each element. The local damage index is given in the following equation:

$$
\mathrm{DI}_{L}=\frac{\theta_{m}-\theta_{r}}{\theta_{u}-\theta_{r}}+\frac{\beta}{M_{y} \theta} E_{T},
$$

where $\mathrm{DI}_{L}$ is the local damage index; $\theta_{m}$ the maximum rotation attained during the load history; $\theta_{u}$ the ultimate rotation capacity of the section; $\theta_{r}$ the recoverable rotation at unloading; $\beta$ a strength degrading parameter; $M_{y}$ the yield moment of the section; and $E_{T}$ the dissipated hysteretic energy. The Park/Ang damage index is a linear combination of the maximum ductility and the hysteretic energy dissipation demand imposed by the earthquake on the structure. The global DI after Park/Ang is presented in the following equation:

$$
\mathrm{GDI}_{\mathrm{PA}}=\frac{\sum_{i=1}^{n} \mathrm{DI}_{L} E_{i}}{\sum_{i=1}^{n} E_{i}},
$$

where $\mathrm{GDI}_{\mathrm{PA}}$ is the global damage index after Park/Ang; $\mathrm{DI}_{L}$ the local damage index after Park/Ang; $E_{i}$ the energy dissipated at location $I$; and $n$ the number of locations at which the local damage is computed. In the same context the localised form of $\mathrm{GDI}_{\mathrm{PA}}$ has been evaluated, as the sum of the recorded $\mathrm{DI}_{L}$ concentrated in each respective level, providing a local damage index relevant to each separate level as shown in the following equation:

$$
\mathrm{LDI}_{\mathrm{PA}}=\frac{\sum_{i=1}^{n} \mathrm{DI}_{L L} E_{i L}}{\sum_{i=1}^{n} E_{i L}},
$$

where $\mathrm{LDI}_{\mathrm{PA}}$ is the level structural damage index after Park/Ang; $\mathrm{DI}_{L L}$ the local damage index after Park/Ang for a 

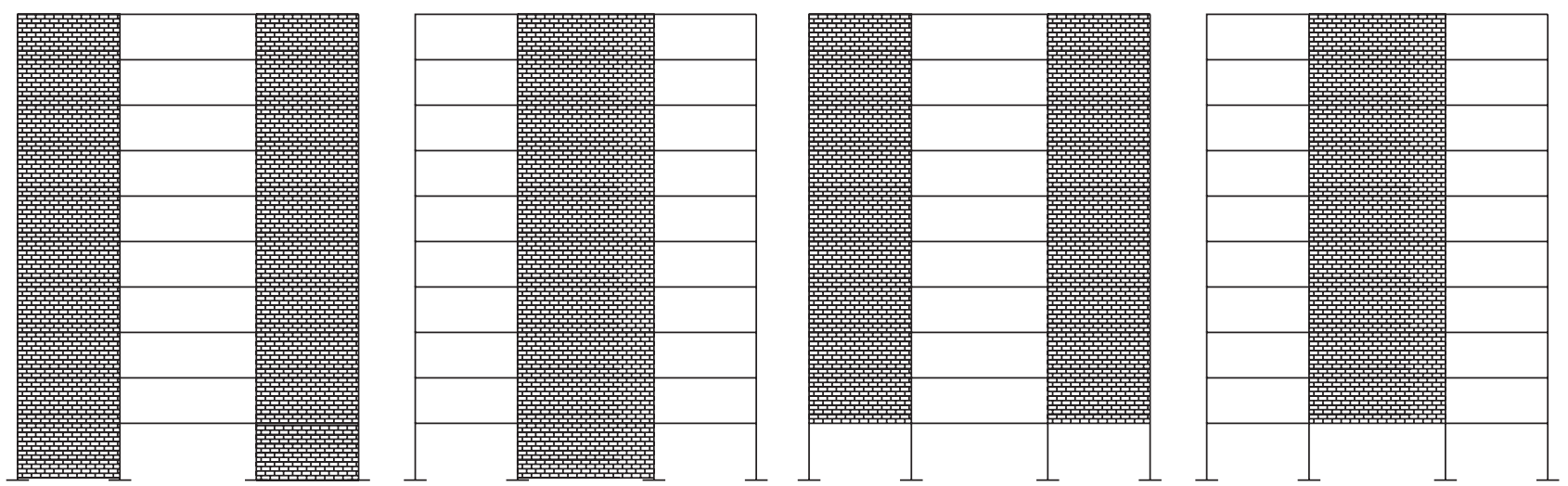

FIGURE 1: Bare frame structure (Frame 0).

particular level; $E_{i L}$ the energy dissipated at location $i$ of the level in question; and $n$ the number of locations at which the local damage is computed.

The maximum interstorey drift ratio (MISDR) is believed to accurately depict the recorded postseismic level of structural and architectural damage of a structure alike. The correlation of MISDR with the above has repeatedly been proven both experimentally as well as from postearthquake site surveys in areas where catastrophic seismic events took place [25] and is widely recognized as an effective tool of damage representation. Furthermore, MISDR is simple in its calculation, as the maximum observed value throughout the recorded individual interstorey drift ratio of each level (LISDR) is given in the following equation:

$$
\operatorname{LISDR}_{i}=\frac{u_{i}-u_{i-1}}{h_{i}} 100,
$$

where $\mathrm{LISDR}_{i}$ is the level interstorey drift ratio; $u_{i}$ is the recorded drift of floor $i ; u_{i-1}$ is the recorded drift of floor; $i-1$ and $h_{i}$ representing the height of floor $i$ and MISDR is the maximum recorded value amongst the total amount of storeys.

\section{Numerical Example}

The geometry, layout, and the structural elements profiles of the 5 different 10 storey building structural models for Frame 0 (bare frame), Frame 1 (2 outer bays bearing infill walls), Frame 2 (central bay bearing infill wall), Frame 3 (same as Frame 1 but with no infill wall present at ground level), and Frame 4 (same as Frame 2 but with no infill wall present at ground level) are given in more detail in Figure 1. Structural detailing was completed by implementing the requirements of both EC3 [21] and the current Greek antiseismic code [20] for steel antiseismic structures. The slabs' thickness has been designed to be $20 \mathrm{~cm}$. The whole design was based on the assumption of a building of importance category 2 (common buildings), low ductility requirements, and type B subsoil (deep deposits of medium dense sand or overconsolidated clay at least $70 \mathrm{~m}$ thick) belonging to a seismic zone I ( $a=0.16 \mathrm{~g}$ ) according to the Greek antiseismic code. In addition, live, snow, and wind loads have also been taken into account as well as the eccentricity of structural element from verticality as per the nominal values pertaining to the relevant construction codes for the design of the structural frame in order to represent a typical steel frame structure. The numerical values of loads, safety factors, and load combinations have been chosen in accordance with Eurocode 1 and 3 and the Greek antiseismic code requirements. The load values used for structural design constitute an imposed load of $5 \mathrm{kN} / \mathrm{m}^{2}$, a snow load of $0.075 \mathrm{kN} / \mathrm{m}^{2}$ for the roof, wind action according to $\mathrm{EC1}$, and concrete slab self-weight assumed to come from a C20/25 concrete slab with a depth of $200 \mathrm{~mm}$, while the infill walls were considered as loads coming from a single nonload bearing infill element of $140 \mathrm{~mm}$ thickness. The frame design parameters as well as element dimensions are presented in Figure 2 and the material utilised was S355.

Next, the creation of the alternative patterns of infill walls to be studied has been realized in such a way as to provide a diverse yet comparable arrangement of infill walls. Namely, Frame 1 that constitutes infill wall present in the two $9 \mathrm{~m}$ wide corner frames and Frame 2 that only furnished infill walls in the middle $12 \mathrm{~m}$ frames both having no infill walls at ground elevation bays.

With the completion of all involved frames' design procedure the implementation of nonlinear dynamic analysis utilizing the 225 spectrum compatible accelerograms followed. The analysis was facilitated with the use of IDARC2D [26] computer program. The results allowed the researchers to effectively evaluate the structural seismic response of all frames on an overall and storey level basis with the extraction of $\mathrm{GDI}_{\mathrm{PA}}, \mathrm{MISDR}$ and $\mathrm{LDI}_{\mathrm{PA}}$, and LISDR values, respectively. This study uses the nominal parameter for the involved steel elements to avoid any bias in the results. Furthermore, the evaluation of the Newmark- $\beta$ method of numerical integration, followed by Newton/Raphson's method for root approximation for every time step, has been carried out as part of IDARC2D analysis operation. A bilinear elastoplastic model with $5 \%$ offset yield strength has been selected to represent the steel elements' behaviour.

The steel material has been modeled as a von Mises material with isotropic hardening. The steel used is S355 according to EN 1993-1-1 [21]. Plastic strains were included with the bilinear elastic-plastic stress-strain curve with 5\% 


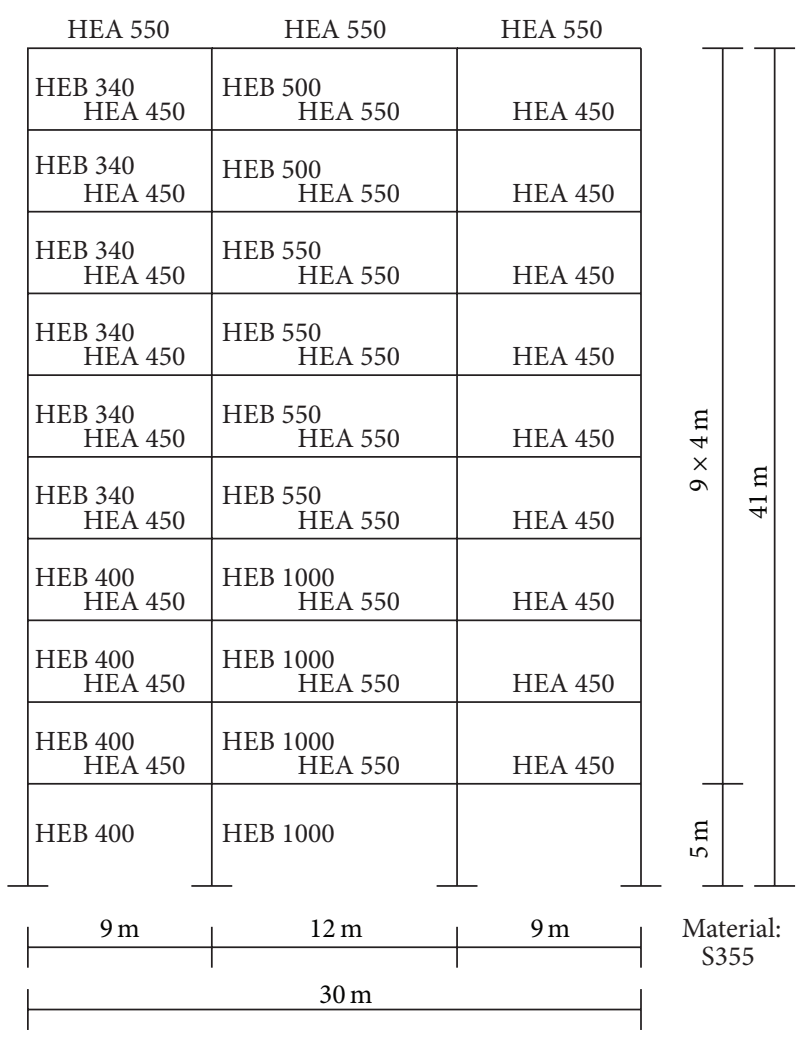

Figure 2: Alternative infill wall arrangements (Frames 1 to 4).

linear strain hardening used to simulate the steel material as per Figure 3, while the ultimate deformation (curvature) for members was specified as the lowest of either the maximum strain at fracture divided by the neutral axis or the maximum plastic moment and a postyield hardening capacity of 0.05 .

The infill elements have been incorporated in the model in the form of diagonal compression struts in the respective subframes. Finally, the smooth hysteretic model that was also used for the infill panels includes the effects of stiffness degradation, strength deterioration, and pinching. The development of the present hysteretic model is based on the nonlinear Bouc-Wen model [26]. For reasons of nonlinear dynamic analysis execution the stress-strain model selected for the infill wall element in compression is presented in Figure 4 and constitutes a parabolic part up to the maximum permissible stress $f_{m}^{\prime}$ and is then reduced at a lower point where it remains constant.

The infill wall element's diagonal struts are considered inactive when in tension, but the combined action of the two diagonals provides the necessary resistance from both directions. The relationship between the horizontal forcedisplacement system of the diagonal strut system is shown in Figure 5(a), while a mild hysteretic Bouc-Wen behaviour model shown in Figure 5(b) has been utilized.

For the calculation of the hysteretic response of the infill wall sections the Saneinejad and Hobbs [27] allowable compression diagonal strut element calculation (5) has been

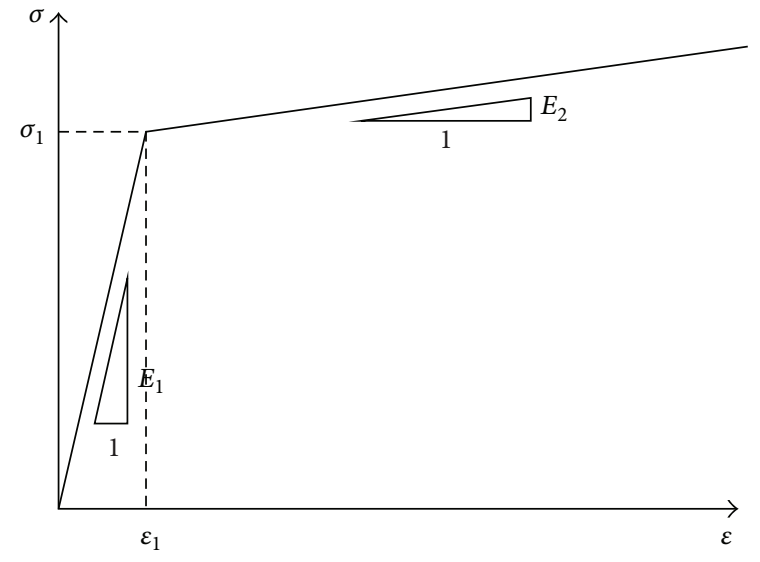

FIGURE 3: Structural steel stress-strain diagram.

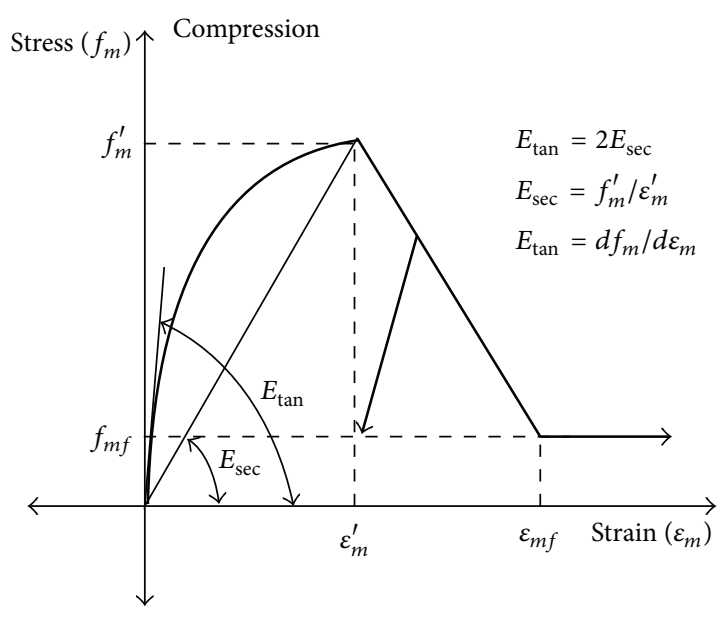

FIGURE 4: Infill wall element stress-strain diagram.

utilised for the permissible compression $f_{a}$ with values of $f_{c}=0.6 * \varphi * f_{m}$ and $\varphi=0.65$ :

$$
f_{a}=f_{c}\left[1-\left(\frac{I_{\text {eff }}}{40 t}\right)^{2}\right] .
$$

The structural response of the building for the artificial accelerograms under investigation was based on the extraction of the overall structural damage index after Park and Ang as well as the maximum interstorey drift ratio in lieu of their ability to consolidate all recorded damages in one arithmetic value. The above selection was made in order to cover both the structural damage due to deformation (MISDR) and also the effects of the combination of deformation and hysteretic energy absorption.

\section{Results and Discussion}

4.1. General Remarks. As previously stated, the main objective of this research is the quantification of the overall seismic response characteristics. In this regard, the focus of interest has been the underlying effect of infill walls in frame structures rather than the response of the infill walls 


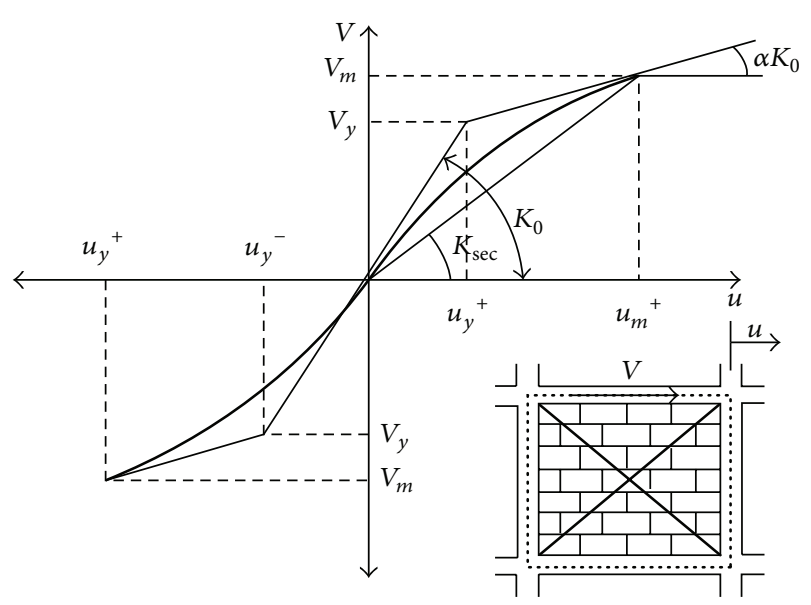

(a)

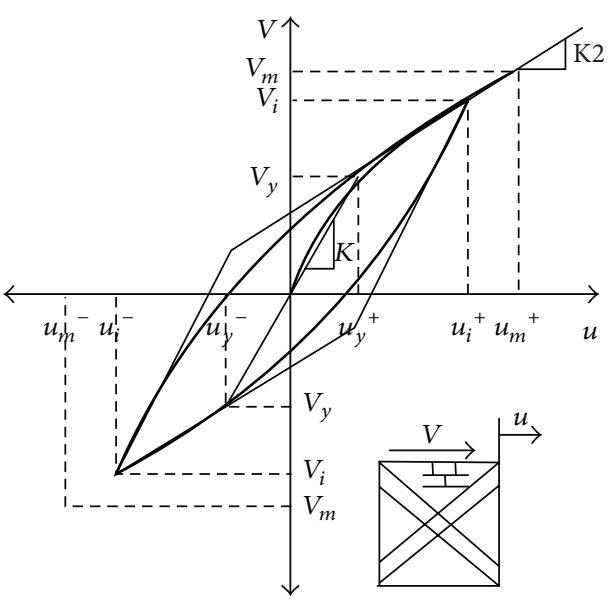

(b)

FIGURE 5: (a) presents the relationship between horizontal force and displacement in infill wall elements. (b) presents the Bouc-Wen model for the mild hysteretic behaviour of infill wall elements.

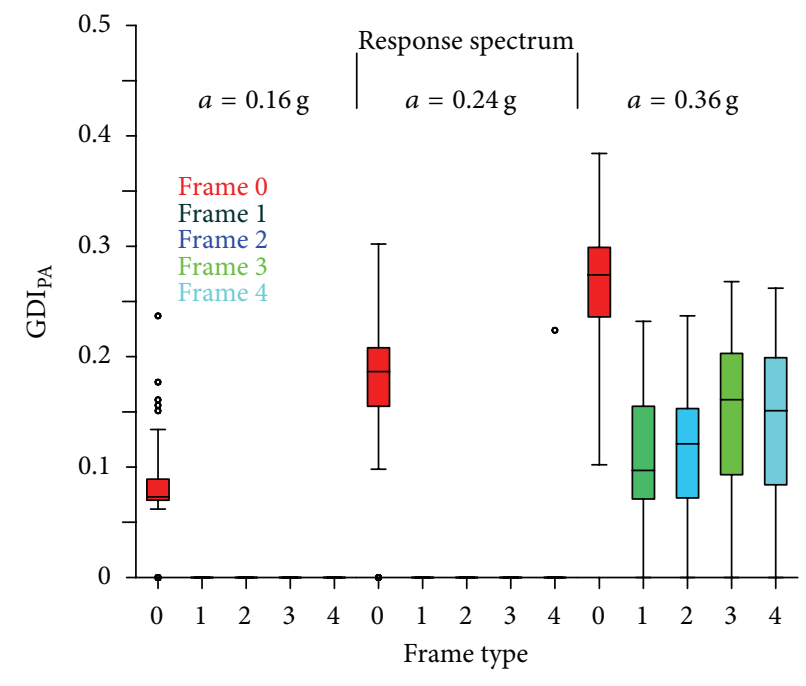

(a)

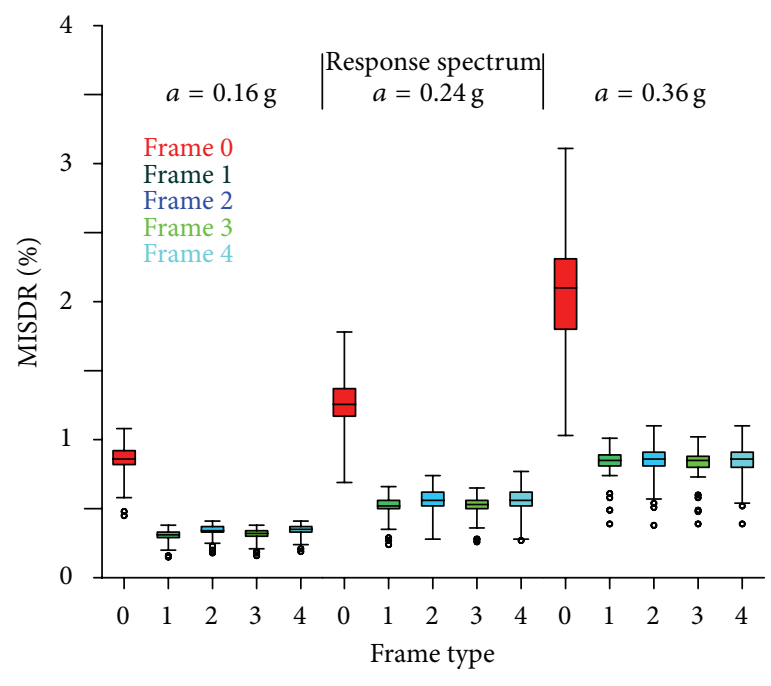

(b)

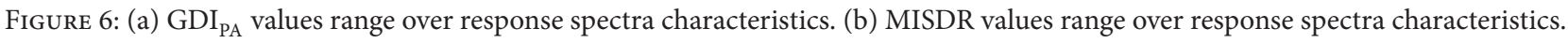

themselves. Therefore, the selection of result indicators has been carried out in such a way as to better facilitate the description of the overall damage distribution and seismic behaviour rather than the microscale seismic effects.

All 4 selected indicators have been separately studied in an attempt to better classify the effects of infill wall inclusion and topology in the seismic behaviour and damage distribution of frame structure as a result from the recorded ISDR and $\mathrm{DI}_{\mathrm{PA}}$ values, respectively. As such, the two different types of structural behaviour indicators have been selected to demonstrate the recorded damage and behaviour in both the overall and local domain.

4.2. Overall Damage Indices. The nonlinear dynamic analysis result data, from the 255 selected spectrum compatible artificial accelerogram induced events, suggested an overall reduction of the recorded average $\mathrm{GDI}_{\mathrm{PA}}$ and MISDR values in the order of $78 \%$ and $60 \%$, respectively, for infill wall bearing frames as presented in Table 1 . An additional reduction of $40 \%$ in the maximum $\mathrm{GDI}_{\mathrm{PA}}$ values as well as a $62 \%$ and $74 \%$ in the minimum and maximum MISDR values has been similarly established between the bare frame and its infill wall bearing counterparts. All aforementioned results indicate the overall beneficial effects the incorporation of infill elements can have in a frame structure in terms of seismic behaviour and structural damage.

To avoid any result obfuscation a clustered approach towards $\mathrm{GDI}_{\mathrm{PA}}$ and MISDR value, in terms of the different seismic characteristics, has been selected to identify the importance of seismic response spectrum and total duration parameters chosen during the artificial accelerogram creation. Figure 6 gives an overview of the recorded GDI $\mathrm{PA}_{\mathrm{PA}}$ and MISDR values in respect to the selected seismic response 


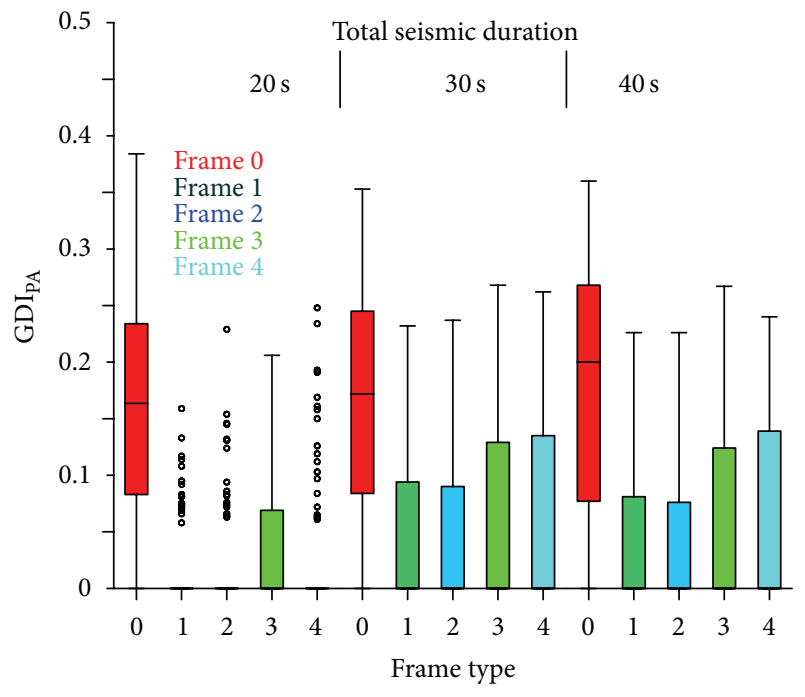

(a)

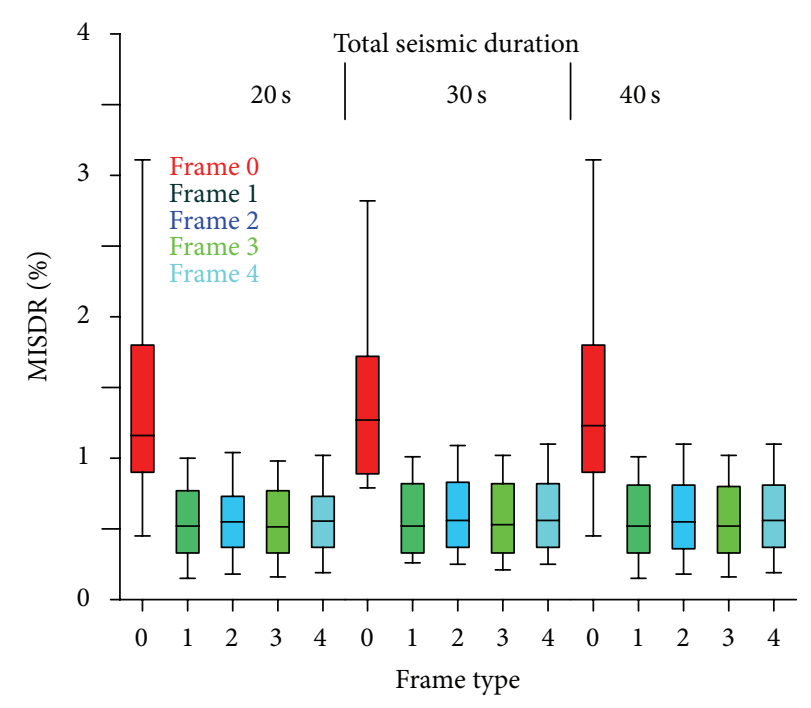

(b)

FIGURE 7: (a) $\mathrm{GDI}_{\mathrm{PA}}$ values range over total duration of seismic events. (b) MISDR values range over total duration of seismic events.

TABLE 1: Overall and reduction values of damage and behaviour indices for all frames.

(a)

\begin{tabular}{lcccc}
\hline & Frame & Min. & Max. & Average \\
\hline \multirow{3}{*}{ GDI $_{\text {PA }}$} & 0 & 0.000 & 0.304 & 0.188 \\
& 1 & 0.000 & 0.162 & 0.035 \\
& 2 & 0.000 & 0.175 & 0.037 \\
& 3 & 0.000 & 0.197 & 0.049 \\
\multirow{3}{*}{ MISDR (\%) } & 4 & 0.000 & 0.191 & 0.047 \\
& 0 & 0.45 & 4.11 & 1.41 \\
& 1 & 0.15 & 1.01 & 0.55 \\
& 2 & 0.18 & 1.10 & 0.59 \\
& 3 & 0.16 & 1.02 & 0.55 \\
& 4 & 0.19 & 1.10 & 0.59 \\
\hline
\end{tabular}

(b)

\begin{tabular}{lcccc}
\hline & \multicolumn{4}{c}{ Percentage reduction against frame 0 (\%) } \\
& Frame & Min. & Max. & Average \\
\hline \multirow{3}{*}{ GDI $_{\text {PA }}$} & 1 & N/A & 47 & 81 \\
& 2 & N/A & 42 & 80 \\
& 3 & N/A & 35 & 74 \\
& 4 & N/A & 37 & 75 \\
\hline \multirow{3}{*}{ MISDR (\%) } & 1 & 67 & 75 & 61 \\
& 2 & 60 & 73 & 58 \\
& 3 & 64 & 75 & 61 \\
& 4 & 58 & 73 & 58 \\
\hline
\end{tabular}

spectrum. The outlier data factors ( $>2.5$ standard deviations) have been separately indicated as small circles. Therefore, a quick overview of the minimum and maximum values (whiskers) as well as the lower and upper quartiles (box) and the median (straight line marking in the box) values can be realised. The recorded data suggests the uniform reduction in terms of MISDR throughout the different seismic response spectra selected, while $\mathrm{GDI}_{\mathrm{PA}}$ values present an effective $100 \%$ reduction in both low and medium seismic region artificial accelerograms.

Similar work has been carried out for the different total duration clusters selected for the creation of the artificial accelerograms presented in Figure 7 in terms of $\mathrm{GDI}_{\mathrm{PA}}$ and MISDR values, respectively. In this case a uniform reduction of the recorded values can be observed indicating a reduced participation of the overall seismic duration in the reduction characteristics of the overall indices studied.

4.3. Level Damage Indices. Similar procedure has been followed in terms of behavioural and damage indicators in the local domain. In this case the interstorey drift ratio (ISDR) for each separate level has been calculated (LISDR) along with the relevant level structural damage index after Park/Ang $\left(\mathrm{LDI}_{\mathrm{PA}}\right)$ for each one of the 255 response spectrum compatible seismic accelerograms utilised.

With the incorporation of a stratified postprocess analysis, in terms of seismic signal's response spectrum compatibility characteristics, the results reveal an effective $100 \%$ reduction in $\mathrm{GDI}_{\mathrm{PA}}$ values recorded for virtually all low and medium seismicity response spectrum originating cases (with $a=0.16 \mathrm{~g}$ and $0.24 \mathrm{~g}$ values). In lieu of data spread in the aforementioned cases the decision to concentrate this study in the identification of structural damage distribution characteristics in the high seismicity region has been made. In this respect the detailed examination of only the cases results relevant to the high seismic response spectrum artificial accelerograms ( $a=0.36 \mathrm{~g}$ ) has been carried out. On the other hand, the structures' seismic behaviour has been examined taking under consideration the full range of results. Figure 8 presents the distribution characteristics of structural damage 


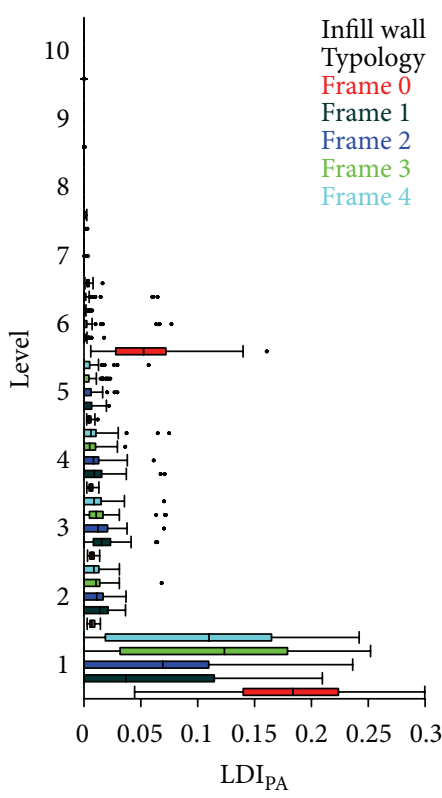

(a)

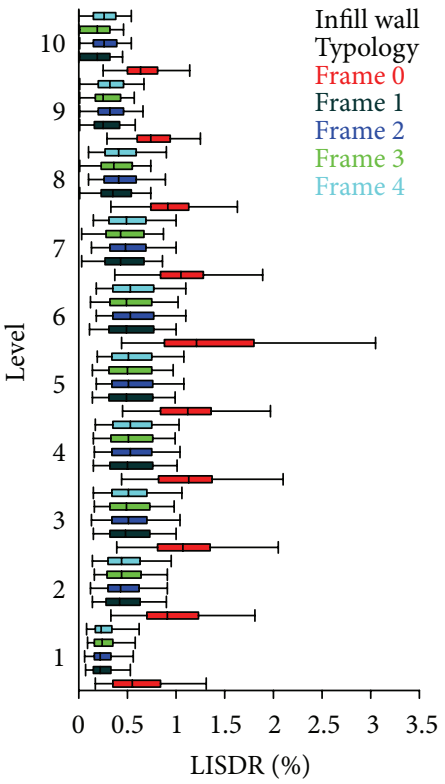

(b)

FIGURE 8: (a) Structural damage distribution characteristics (LDIPA) for $a=0.36 \mathrm{~g}$ response spectrum compatible artificial accelerograms (75 cases). (b) Structural behaviour distribution characteristics (LISDR) for all available data (225 cases).

TABLE 2: Contribution of sixth level damage index in $\mathrm{GDI}_{\mathrm{PA}}$ and reduction values over Frame 0.

\begin{tabular}{|c|c|c|c|c|c|c|c|c|c|}
\hline \multirow{3}{*}{ 6th level } & \multicolumn{9}{|c|}{ Frame typology } \\
\hline & \multicolumn{5}{|c|}{$\mathrm{GDI}_{\mathrm{PA}}$ contribution } & \multicolumn{4}{|c|}{ Reduction against Frame 0 (\%) } \\
\hline & 0 & 1 & 2 & 3 & 4 & 1 & 2 & 3 & 4 \\
\hline Average & 0.20 & 0.01 & 0.05 & 0.00 & 0.03 & 95.0 & 75.0 & 100 & 85.0 \\
\hline $\begin{array}{l}\text { 3rd } \\
\text { quartile }\end{array}$ & 0.21 & 0.01 & 0.01 & 0.00 & 0.01 & 95.2 & 95.2 & 100 & 95.2 \\
\hline Maximum & 0.30 & 0.04 & 0.15 & 0.02 & 0.12 & 86.7 & 50.0 & 93.3 & 60.0 \\
\hline
\end{tabular}

and behaviour as recorded through the $\mathrm{LDI}_{\mathrm{PA}}$ and LISDR indices, respectively, for each of the 10 levels comprising the structure under investigation. In this case, the outlier data factors ( $>2.5$ standard deviations) have been separately indicated and not included for the determination of extreme values to avoid result obfuscation of the recorded min. and max. points due to these extreme contributors.

As outlined before, in terms of structural response the results have been divided into two distinct characteristics, structural damage and structural behaviour. Result data suggest the promotion of structural damage concentration in the first and sixth level for the bare frame structure (Frame 0) expressed through the respective $\mathrm{LDI}_{\mathrm{PA}}$ distribution creating potentially dangerous conditions for the manifestation of localised damages that lead to the creation of an unfavourable structural damage mechanism. Furthermore, due to the particular structural and seismic characteristics of the analytical models examined, there is a seemingly large influence of the 6th elevation in both structural behaviour and damage distribution where infill wall elements seem to address by distrusting structural damage in a series of levels ranging, predominantly, from first to sixth elevation rather than concentrate damage on the 1st and 6th elevations as is the case with the bare frame (Frame 0). Data presented in Table 2 suggests a quantifiable improvement of structural damage distribution characteristics of infill wall bearing frames against their bare frame counterpart with a significant reduction in the recorded sixth level average $\mathrm{LDI}_{\mathrm{PA}}$ values of $95 \%, 75 \%, 100 \%$, and $85 \%$ for Frame 1, Frame 2, Frame 3, and Frame 4, respectively.

Furthermore, a comparison of the first to sixth level's $\mathrm{LDI}_{\mathrm{PA}}$ versus the structures' $\mathrm{GDI}_{\mathrm{PA}}$ distribution ratio reveals the overall structural damage distribution uniformity demonstrated by Frames 1 and 2. Data suggests that infill frames presented and more evenly distributed damage characteristics with a $57: 13: 16: 10: 03: 01$ and $61: 10: 12: 08$ : 03: $05 \mathrm{LDI}_{\mathrm{PA}}$ versus $\mathrm{GDI}_{\mathrm{PA}}$ percentage ratio for Frames 1 and 2, respectively, against the 69:03:03:02:02:20 ratio recorded in their bare frame counterpart.

In terms of structural behaviour as expressed through interstorey drift ratio (LISDR) for each individual level Figure 9 presents the relevant values for seismic excitations compatible to $a=0.16 \mathrm{~g}, 0.24 \mathrm{~g}$, and $0.36 \mathrm{~g}$ in Figures 9(a), 9(b), and 9(c), respectively. In this respect the particular 


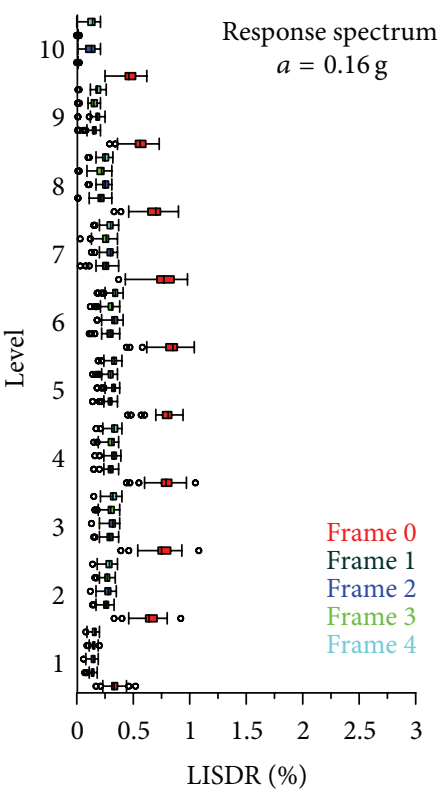

(a)

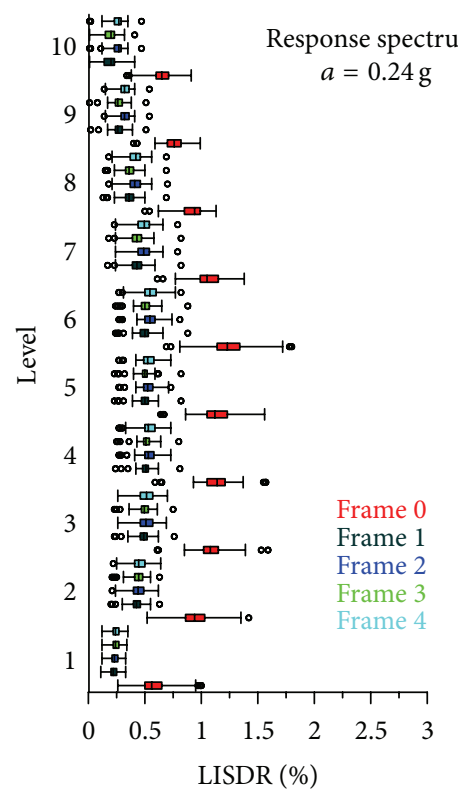

(b)

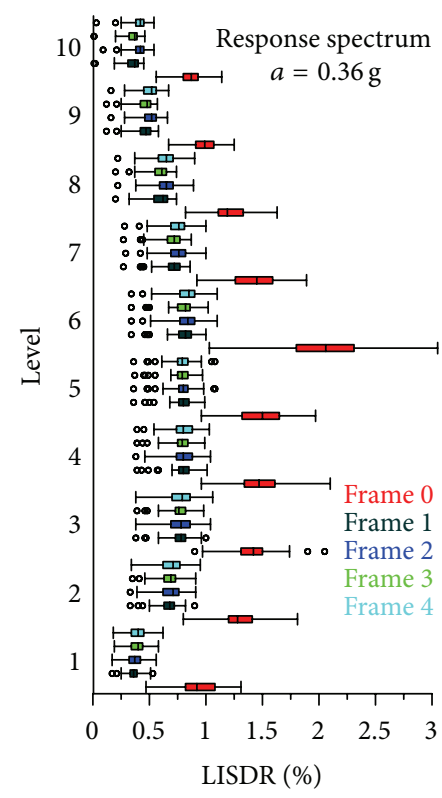

(c)

FIGURE 9: (a) All frame typologies recorded LISDR values for $a=0.16$ g. (b) All frame typologies recorded LISDR values for $a=0.24$ g. (c) All frame typologies recorded LISDR values for $a=0.36 \mathrm{~g}$.

TABLE 3: Average recorded LISDR value reduction (\%).

\begin{tabular}{|c|c|c|c|c|c|c|c|c|c|c|c|}
\hline \multirow{2}{*}{ Frame } & \multirow{2}{*}{ Response spectrum } & \multicolumn{10}{|c|}{ Level } \\
\hline & & 1 & 2 & 3 & 4 & 5 & 6 & 7 & 8 & 9 & 10 \\
\hline \multirow{3}{*}{1} & $0.16 \mathrm{~g}$ & 59 & 60 & 61 & 62 & 63 & 66 & 67 & 70 & 75 & 98 \\
\hline & $0.24 \mathrm{~g}$ & 62 & 55 & 56 & 56 & 57 & 61 & 60 & 61 & 66 & 74 \\
\hline & $0.36 \mathrm{~g}$ & 61 & 48 & 46 & 46 & 48 & 62 & 50 & 51 & 54 & 60 \\
\hline \multirow{3}{*}{2} & $0.16 \mathrm{~g}$ & 57 & 58 & 58 & 59 & 60 & 61 & 62 & 64 & 68 & 75 \\
\hline & $0.24 \mathrm{~g}$ & 60 & 53 & 53 & 53 & 53 & 57 & 55 & 56 & 58 & 60 \\
\hline & $0.36 \mathrm{~g}$ & 60 & 47 & 45 & 46 & 47 & 60 & 48 & 47 & 49 & 53 \\
\hline \multirow{3}{*}{3} & $0.16 \mathrm{~g}$ & 55 & 59 & 61 & 62 & 63 & 65 & 67 & 70 & 75 & 98 \\
\hline & $0.24 \mathrm{~g}$ & 59 & 54 & 55 & 55 & 56 & 60 & 60 & 61 & 65 & 73 \\
\hline & $0.36 \mathrm{~g}$ & 57 & 47 & 46 & 47 & 48 & 62 & 51 & 51 & 54 & 60 \\
\hline \multirow{3}{*}{4} & $0.16 \mathrm{~g}$ & 54 & 56 & 58 & 58 & 59 & 60 & 62 & 64 & 68 & 74 \\
\hline & $0.24 \mathrm{~g}$ & 58 & 52 & 53 & 53 & 53 & 57 & 55 & 55 & 58 & 60 \\
\hline & $0.36 \mathrm{~g}$ & 57 & 46 & 45 & 46 & 47 & 60 & 48 & 47 & 49 & 53 \\
\hline
\end{tabular}

differences between the alternative infill walls' topologies can be reviewed as per the recorded seismic response influence at different levels of seismic excitation dictated through the selection of their respective response spectrum.

The reduction in the recorded LISDR values for all infill wall frame typologies against the bare frame has been summarized in Table 3 as observed on a level to level basis.

Figure 10 highlights the similarities in structural behaviour presented between frame typologies with comparable area of infill wall patterns irrespective of the existence or not of infill walls in the first elevation (ground floor) frames. It is therefore concluded that little difference can be attributed in the first elevation infill walls and those differences register in the reduction values of the ground floor only, in respect to the structures seismic behaviour in terms of observed inter storey drift ratio.
In light of the above and in terms of seismic behaviour, the study of the effect of infill walls' alternative typologies measured through the reduction of the average recorded LISDR values against the bare frame can be deemed appropriate to be carried out utilizing Frames 1 and 2. Figure 11 presents the LISDR reduction for Frames 1 and 2 in terms of percentage of the bare frame (Frame 0) LISDR values across the three different response spectra selected. The results indicate the tendency of infill wall presence towards the cancelation of the increased sixth level drift of the bare frame demonstrating the beneficial effect of their incorporation. Furthermore, the progressive convergence of the reduction values between the different frames in different strength seismic excitations can be deemed as an indication of the overall influence of infill walls against the specific typologies studied. Therefore, the tendency for the infill wall bearing frames to act in a similar 


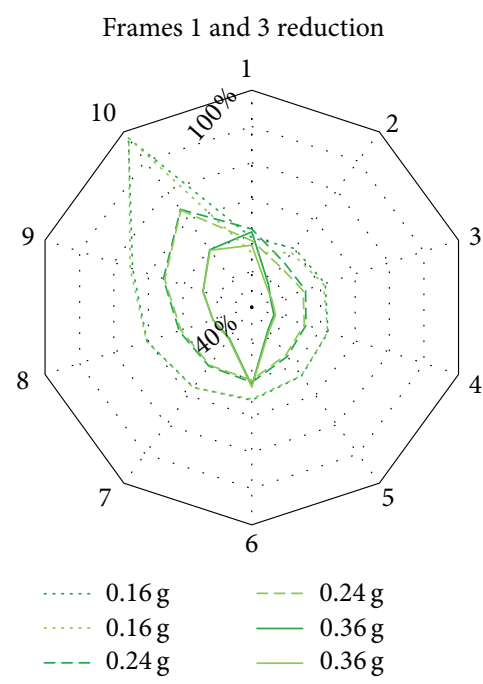

(a)

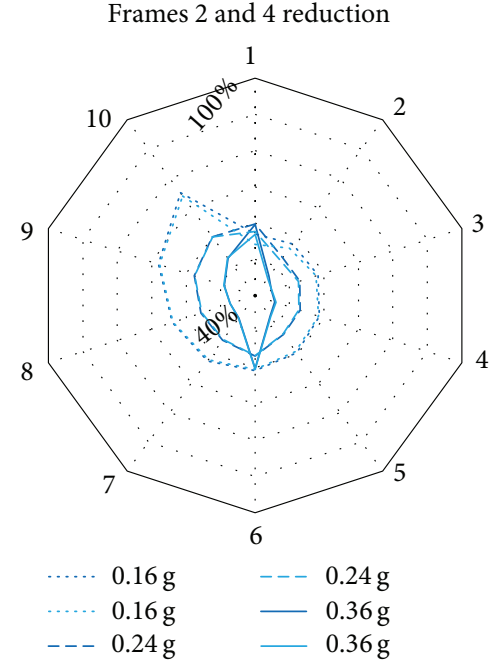

(b)

FIGURE 10: (a) Level reduction values for infill wall bearing Frames 1 and 3 over Frame 0. (b) Level reduction values for infill wall bearing Frames 2 and 4 over Frame 0.

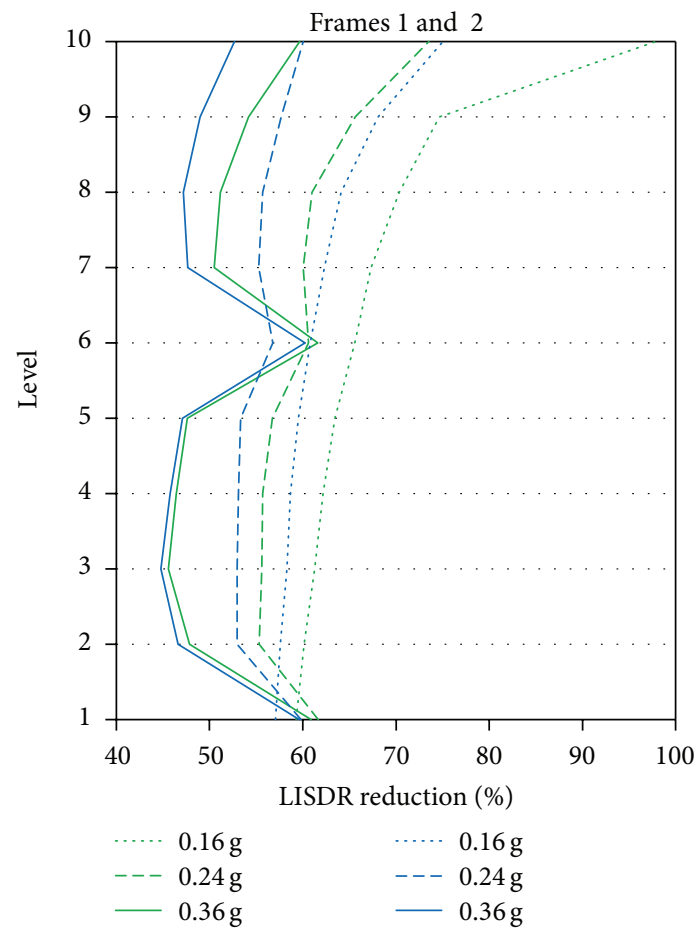

FIGURE 11: Level average reduction values recorded for Frames 1 and 2 against Frame 0.

manner in increasing seismic load, with little respect to the particular infill wall topology conditions, advocates an additional point for consideration by further demonstrating the suitability of infill wall incorporation in the structural system of either new designs or cases of structural rehabilitation.

Table 4 summarises the recorded reductions in the average values of LISDR between the bare frame and its infill
TABLE 4: Average LISDR reduction (\%) recorded over the whole structure.

\begin{tabular}{lccc}
\hline \multirow{2}{*}{ LISDR reduction (\%) } & \multicolumn{3}{c}{ Response spectrum (a) } \\
& $0.16 \mathrm{~g}$ & $0.24 \mathrm{~g}$ & $0.36 \mathrm{~g}$ \\
\hline Frame & & & \\
1 & 68 & 61 & 54 \\
2 & 62 & 56 & 51 \\
3 & 68 & 60 & 54 \\
4 & 61 & 55 & 50 \\
\hline
\end{tabular}

walled counterparts for each of the respective response spectrum compatible seismic excitation groups. In this respect, the progressively smaller influence of infill walls in the structural seismic behaviour is indicated by a $61 \%$ to $68 \%$ reduction of the average LISDR result values for seismic events corresponding to a response spectrum with $a=0.16 \mathrm{~g}$. Similarly, a reduction of $55 \%$ to $61 \%$ and $50 \%$ to $54 \%$ has been recorded for seismic events corresponding to a response spectrum of $a=0.24 \mathrm{~g}$ and $0.36 \mathrm{~g}$, respectively.

Once more, the distinctively greater improvement which is seismic response of Frames 1 and 3 over Frames 2 and 4 is suggested by the results, indicated by the greater LISDR reduction values observed. It therefore consolidates the relevant findings over the infill wall topology influence on the recorded structural response under seismic excitation. Moreover, the converging nature of the reduction values indicates the diminishing effect of these differences in infill wall topologies as progressing towards stronger seismic excitations.

4.4. Results Summary. A closer look at the outcomes of this work suggests an overall reduction of the recorded average $\mathrm{GDI}_{\mathrm{PA}}$ and MISDR values in the order of $78 \%$ and $60 \%$, 
respectively, between infill and noninfill bearing frames. Additionally, a reduction of $40 \%$ in the maximum $\mathrm{GDI}_{\mathrm{PA}}$, as well as a $62 \%$ and $74 \%$ in the minimum and maximum MISDR, values has been similarly established between the bare frame and its infill wall containing steel structure counterparts.

The data suggests a uniform reduction in terms of MISDR throughout the different seismic response spectra selected. On the other hand, $\mathrm{GDI}_{\mathrm{PA}}$ values present an effective $100 \%$ reduction in both low and medium seismic region artificial accelerograms ( $a=0.16 \mathrm{~g}$ and $0.24 \mathrm{~g}$ ), while measurable improvement has been recorded in the high seismicity region response spectrum compatible accelerograms ( $a=0.36 \mathrm{~g}$ ). The above indicates the strong influence of the overall response spectra seismic characteristics in the effectiveness of infill walls as seismic behaviour altering elements. On the other hand, a uniform reduction of the recorded ISDR and $\mathrm{DI}_{\mathrm{PA}}$ values observed hints towards the reduced participation of the overall seismic duration in the seismic response characteristic alteration of infill walls effectiveness. Therefore, indicating that total duration characteristics present a less significant seismic feature, with only a small contribution to the overall structural seismic response behaviour.

In terms of structural response on a storey level, represented by the recorded LISDR and $\mathrm{LDI}_{\mathrm{PA}}$ values, the results indicated the difference of influence between the structural damage distribution and structural behaviour characteristics. This becomes evident by the quantifiable improvement of structural damage distribution characteristics, of infill wall bearing frames against their bare frame counterparts. This has been demonstrated with the observed significant reduction in the recorded sixth level average $\mathrm{LDI}_{\mathrm{PA}}$ values of $95 \%, 75 \%, 100 \%$, and $85 \%$ for Frames 1, 2, 3, and 4, respectively. In this regard, the results suggest the alteration of the predominant damage concentration in the first and sixth level for the bare frame structure (Frame 0 ) with a more distributed allocation of the recorded structural damage in a series of levels. In more detail, a comparison of first to sixth level's $\mathrm{LDI}_{\mathrm{PA}}$ versus $\mathrm{GDI}_{\mathrm{PA}}$ distribution ratio revealed the overall structural damage distribution uniformity that is demonstrated by Frames 1 and 2 with a $57: 13: 16: 10: 03: 01$ and $61: 10: 12: 08: 03: 05 \mathrm{LDI}_{\mathrm{PA}}$ versus $\mathrm{GDI}_{\mathrm{PA}}$ percentage damage distribution ratio against the 69:03:03:02:02:20 recorded for Frame 0 . This effectively illustrates a strong case in favour of the beneficial effects of infill wall existence in the overall seismic behaviour of frame structures. Similarly for seismic behaviour, as expressed through the interstorey drift (ISDR) characteristics of magnitude and distribution, significant improvements were recorded in all cases examined for all frames under consideration. Most prominently, Frame 1 and 3 topologies recorded better results and bigger influence in the improvement of the overall structural behaviour. Furthermore, LISDR results indicate a converging trend between the improvement values of the 4 infill wall topologies for increasing seismic excitation characteristics but remain far superior over the bare frame counterpart. In this respect LISDR reduction values of $61 \%$ to $68 \%, 55 \%$ to $61 \%$, and $50 \%$ to $54 \%$ were recorded for seismic events corresponding to a response spectrum of $a=0.16 \mathrm{~g}, 0.24 \mathrm{~g}$, and $0.36 \mathrm{~g}$ between infill wall and bare frame structures.

\section{Conclusions}

This paper investigated the influence of alternative infill wall topologies in terms of a frame structure's seismic behaviour and damage distribution characteristics. The work was carried out with the utilization of a set of 225 Greek antiseismic code spectrum compatible artificial accelerograms and the execution of nonlinear dynamic analyses for all individual cases to obtain the relevant structural response data. Structural damage results were quantified with the help of the global structure damage index (GDI) after Park/Ang $\left(\mathrm{GDI}_{\mathrm{PA}}\right)$ and the maximum interstorey drift ratio (MISDR), respectively. Their level-wise counterparts were utilised to identify the structural behaviour in the forms of level damage index after Park/Ang $\left(\mathrm{LDI}_{\mathrm{PA}}\right)$ and the level interstorey drift ratio (LISDR).

Based on the results presented, a significant reduction in both $\mathrm{GDI}_{\mathrm{PA}}$ and MISDR indices for all examined selected infill wall topologies was recorded, vividly demonstrating the improvement in terms of structural damage and seismic behaviour, respectively. The data suggests that a significant reduction in the observed interstorey drift ratio is achieved with the incorporation of any infill wall typology without significant impact in the individual LISDR distribution characteristics for any of the investigated infill wall typologies. In terms of the $\mathrm{LDI}_{\mathrm{PA}}$ recorded values, representing the recorded structural damage on each individual level, a significant reduction can be observed followed by a differentiation in damage distribution. The most notable contributions of infill walls in terms of structural damage besides the significant reduction in $\mathrm{GDI}_{\mathrm{PA}}$ values observed were the improvement of the damage distribution characteristics where the first and sixth level damage concentration mode recorded for the bare frame has greatly improved from the first to sixth level structural distribution mode. Thus, by avoiding damage concentration and promoting a structurally beneficial spread of the damage into different elevations effectively improved the overall structural damage response in both magnitude (DIPA) as well as its distribution characteristics.

Care shall be taken to avoid generalizations that would not take into account the localized impact of infill elements to the frame structure due to stress localization, especially in the case of weak frame structures. In this regard, due diligence needs to be spent to avoid introducing plan irregularities that might introduce inelastic deformation demands that could concentrate in the part of the building which has more sparse infills. As a matter of further work to be carried out the estimation of the reduction of the drift demands as a function of different structures (e.g., buildings with different number of stories, designed for different ductility classes), of diverse types of infill, and of "density" or area of walls in the bays of the frame could be carried out in the future.

In this work the use of nonstructural elements as means of improving frame structural seismic behaviour has been investigated and important aspects of structural response 
have been highlighted demonstrating the suitability of such element implementation beyond their intended architectural scope provided that consideration was spent to take into account all possible stress conditions that such an intervention might give rise to. This work gave rise to elements of the suitability of infill walls in the structural rehabilitation of frame structures in all infill typologies while demonstrated the lesser improvement recorded when the infill element layout creates a soft storey effect. Furthermore, by testing different infill wall topologies this work advocated the improved seismic response characteristics against similar bare frame structures in terms of structural damage and behaviour, while the nature of infill wall topology specifics, based on possible architectural constraints and design requirements, does not significantly negate these effects. It is therefore the conclusion of this research that infill walls can play an important role in frame buildings seismic behaviour both with their inclusion in the original design or when utilized as a seismic retrofit to improve a structure's characteristics.

\section{References}

[1] T. Paulay and M. J. N. Priestley, Seismic Design of Reinforced Concrete and Masonry Buildings, John Wiley \& Sons, Hoboken, NJ, USA, 1992.

[2] L. Di Sarno and A. S. Elnashai, "Bracing systems for seismic retrofitting of steel frames," Journal of Constructional Steel Research, vol. 65, no. 2, pp. 452-465, 2009.

[3] ATC-33, "NEHRP guidelines for the seismic rehabilitation of buildings," Tech. Rep. FEMA 273, Federal Emergency Management Agency, Washington, DC, USA, 1997.

[4] R. H. Wood, "The stability of tall buildings," ICE Proceedings, vol. 11, no. 1, pp. 69-102, 1958.

[5] M. Wakabayashi, "Behaviour of systems," in Proceedings of the 6th World Conference on Earthquake Engineering (WCEE '77), pp. 65-76, New Delhi, India, 1977.

[6] R. E. Klingner and V. V. Bertero, "Earthquake resistance of infilled frames," Journal of The Surveying and Mapping Division, vol. 104, no. 6, pp. 973-989, 1978.

[7] J. L. Dawe, A. B. Schriver, and C. Sofocleous, "Masonry infilled steel frames subjected to dynamic load," Canadian Journal of Civil Engineering, vol. 16, no. 6, pp. 877-885, 1989.

[8] Y. Yamazaki, S. Okamoto, T. Kaminosono, and M. Teshigawara, "Seismic tests on a five storey full scale reinforced masonry building," in Proceedings of the 5th North American Masonry Conference (NAMC '90), vol. 1, no. 2, pp. 69-80, University of Illinois at Urbana-Champaign, Champaign, Ill, USA, 1990.

[9] S. Albanesi, T. Albanesi, and F. Carboni, "The influence of infill walls in RC frame seismic response," in High Performance Structures and Materials II, C. A. Brebbia and W. P. De Wilde, Eds., pp. 621-630, WIT Press, Southampton, UK, 2004.

[10] G. Mondal and S. K. Jain, "Lateral stiffness of masonry infilled reinforced concrete (RC) frames with central opening," Earthquake Spectra, vol. 24, no. 3, pp. 701-723, 2008.

[11] R. Zarnic and S. Gostic, "Masonry infilled frames as an effective structural subassemblage," in Proceedings of the International Workshop on Seismic Design Methodologies for the Next Generation of Codes, pp. 335-346, August Aimé Balkema, Bled, Slovenia, 1997.
[12] S. V. Polyakov, Masonry in Framed Buildings: An Investigation Into the Strength and Stiffness of Masonry Infilling, Gosudarstvennoe Izdatel'stvo Literatury Po stroitel'stvu Iarkhitekture, Moscow, Russia, English translation by G. L. Cairns, National Lending Library for Science and Technology, Yorkshire, Boston, UK, 1956.

[13] B. S. Smith and A. Coull, Tall Building Structures: Analysis and Design, John Wiley \& Sons, Hoboken, NJ, USA, 1991.

[14] D. D'Ayala, J. Worth, and O. Riddle, "Realistic shear capacity assessment of infill frames: comparison of two numerical procedures," Engineering Structures, vol. 31, no. 8, pp. 1745-1761, 2009.

[15] B. S. Smith and C. Carter, "A method of analysis for infilled frames," ICE Proceedings, vol. 44, no. 1, pp. 31-48, 1969.

[16] M. Bruneau and T. Bhagwagar, "Seismic retrofit of flexible steel frames using thin infill panels," Engineering Structures, vol. 24, no. 4, pp. 443-453, 2002.

[17] G. Sun, R. He, G. Qiang, and Y. Fang, "Cyclic behavior of partially-restrained steel frame with RC infill walls," Journal of Constructional Steel Research, vol. 67, no. 12, pp. 1821-1834, 2011.

[18] A. A. Tasnimi and A. Mohebkhah, "Investigation on the behavior of brick-infilled steel frames with openings, experimental and analytical approaches," Engineering Structures, vol. 33, no. 3, pp. 968-980, 2011.

[19] A. Mohebkhah, A. A. Tasnimi, and H. A. Moghadam, "Nonlinear analysis of masonry-infilled steel frames with openings using discrete element method," Journal of Constructional Steel Research, vol. 64, no. 12, pp. 1463-1472, 2008.

[20] OASP, “Greek antiseismic code," Greek Ministry of Environment and Public Works, Athens, Greece, 2003, (Greek).

[21] CEN, “EN 1993: Eurocode 3-design of steel structures," European Committee for Standardization, Brussels, Belgium, 1993.

[22] CEN, "EN 1998: Eurocode 8-earthquake resistance design of structures," European Committee for Standardization, Brussels, Belgium, 2004.

[23] D. A. Gasparini and E. H. Vanmarcke, "SIMQKE, a program for artificial motion generation," User's manual and documentation, Publication no. R76-4, Department of Civil Engineering, MIT, Cambridge, Mass, USA, 1976.

[24] Y.-J. Park and A. H.-S. Ang, "Mechanistic seismic damage model for reinforced concrete," Journal of Structural Engineering, vol. 111, no. 4, pp. 722-739, 1985.

[25] S. K. V. Gunturi and H. C. Shah, "Building specific damage estimation," in Proceedings of the 10th World Conference On Earthquake Engineering (WCEE '92), pp. 6001-6006, Madrid, Spain, 1992.

[26] A. M. Reinhorn, H. Roh, M. Sivaslvan et al., "IDARC 2D version 7. 0: a program for the inelastic damage analysis of structures," Tech. Rep. MCEER-09-0006, State University of New York, Buffalo, NY, USA, 2009.

[27] A. Saneinejad and B. Hobbs, "Inelastic design of infilled frames," Journal of Structural Engineering, vol. 121, no. 4, pp. 634-650, 1995. 


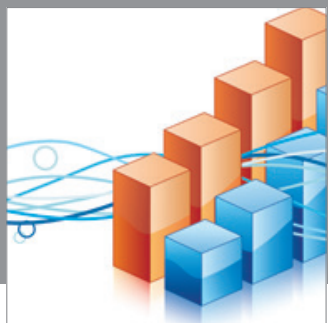

Advances in

Operations Research

mansans

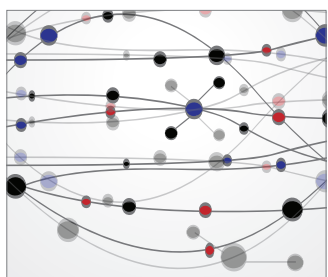

The Scientific World Journal
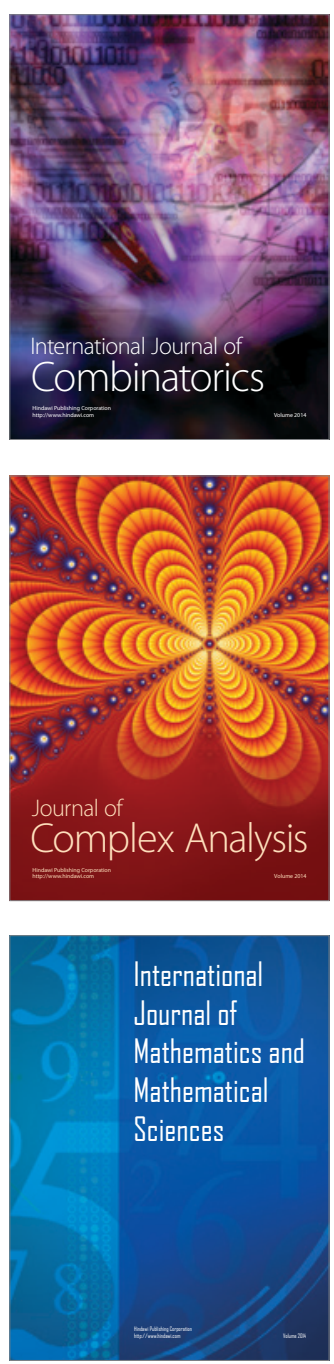
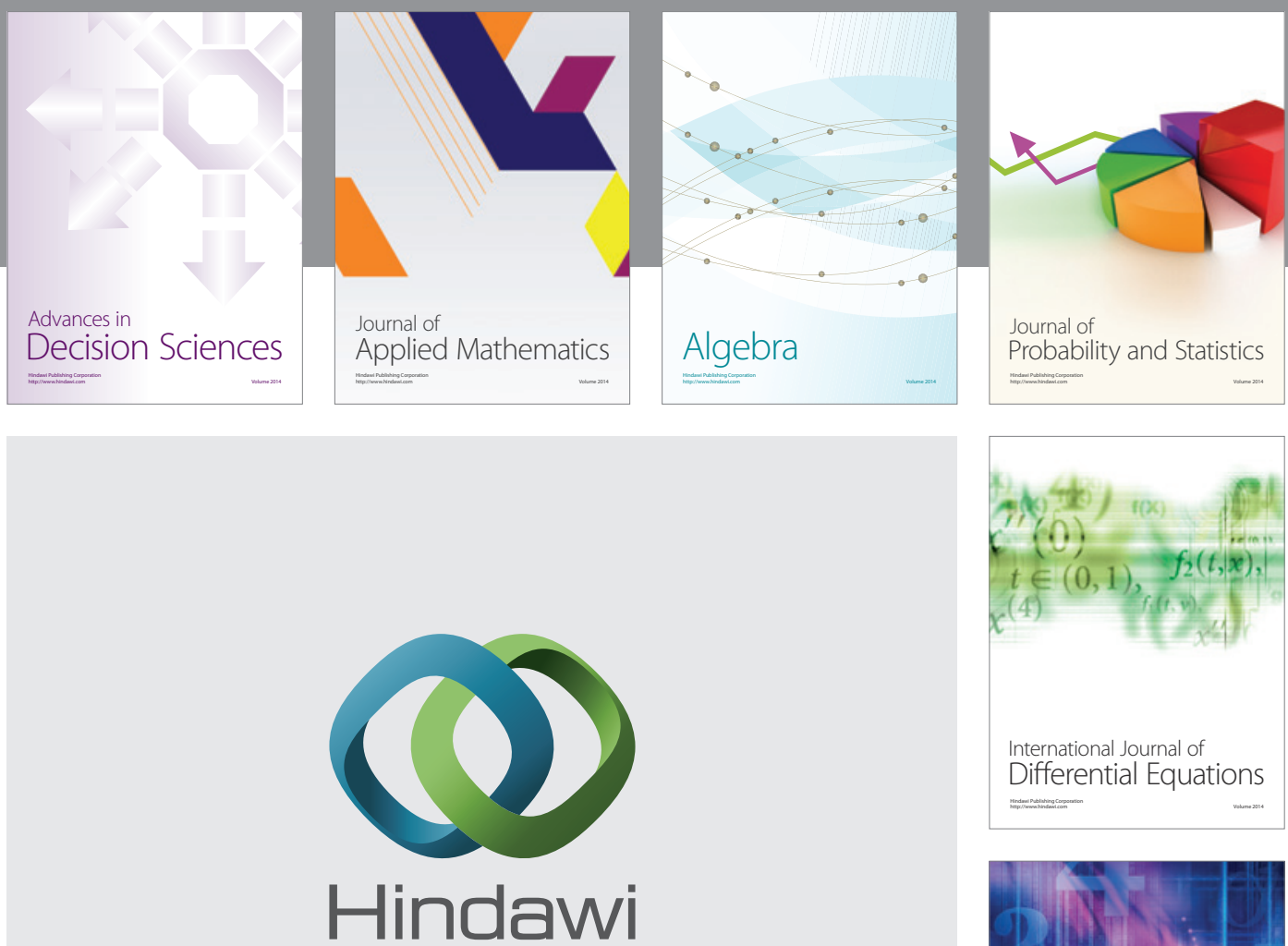

Submit your manuscripts at http://www.hindawi.com
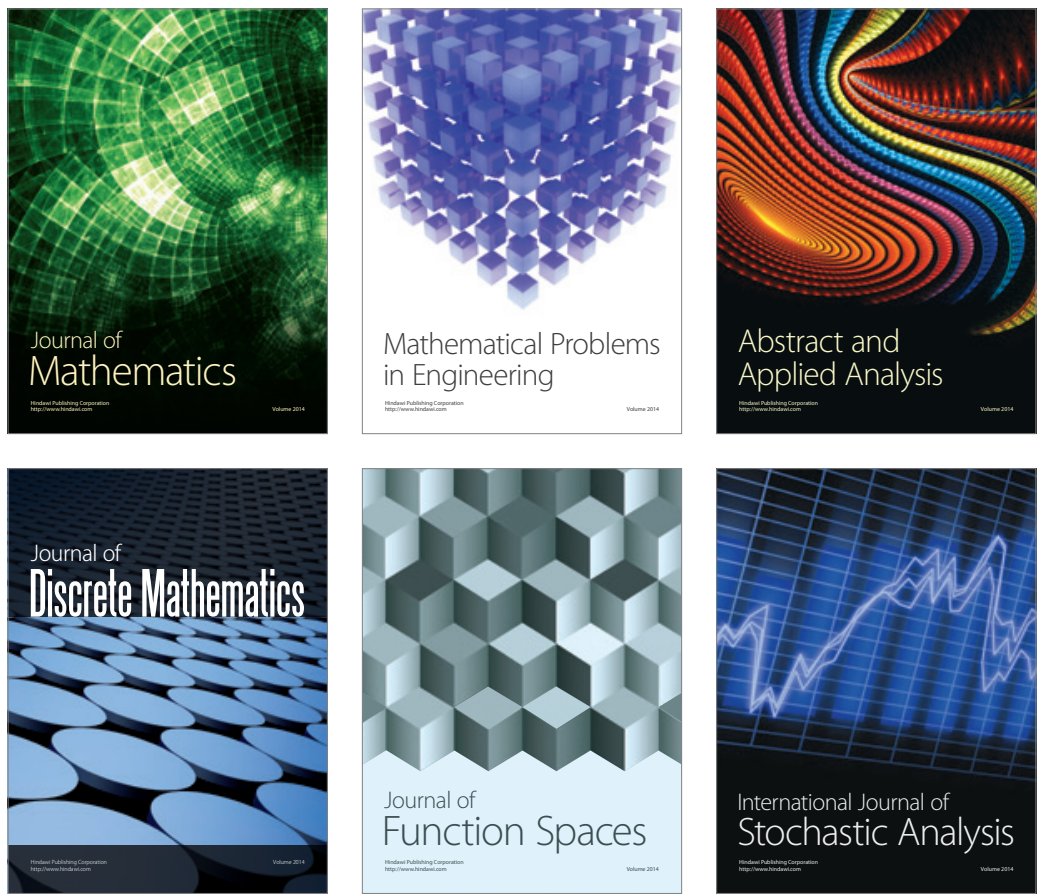

Journal of

Function Spaces

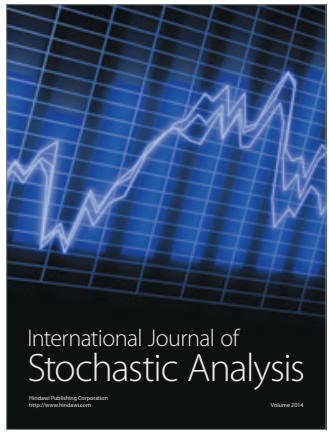

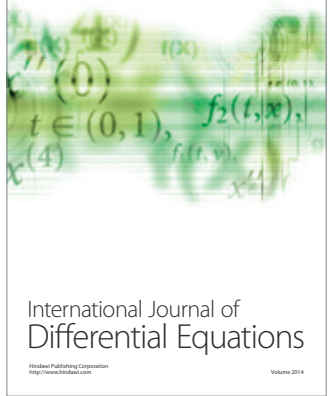
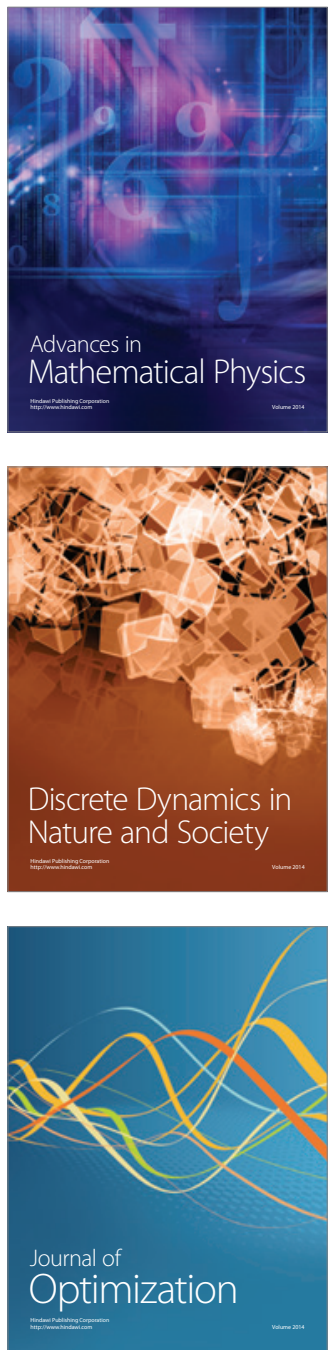